\title{
PENGARUH MOTIVASI KERJA TERHADAP SEMANGAT KERJA DAN KINERJA PEGAWAI DINAS PENDIDIKAN DAN KEBUDAYAAN KABUPATEN KEPULAUAN MERANTI
}

\author{
Syaifuddin 1 \\ Indra Prasetyo ${ }^{2}$ \\ Mei Indrawati ${ }^{3}$
}

\author{
Program Magister Manajemen Universitas Wijaya Putra Surabaya $a^{1,2,3}$ \\ email: ardiantoardani98@gmail.com
}

\begin{abstract}
This research aims to analyze and test the impact of work motivation on employee morale, the impact of employee morale on employee performance, the impact of work motivation on employee performance, and the impact of work motivation on employee performance. This research is a type of research that uses an explanatory research model, this research has a quantitative approach using a population of 77 people with details of 32 civil servants and 45 non-civil servants and a sample of 76 people. The analytical method used in this research is path analysis. Based on the test findings, it shows that work motivation has a positive and significant effect on employee morale, employee work enthusiasm has a positive and significant impact on employee work results, work motivation has a positive and significant impact on performance. Work motivation has a positive and significant impact on employee performance through enthusiasm for work.
\end{abstract}

Keywords: motivation, morale, performance.

\section{PENDAHULUAN}

Keberhasilan organisasi saat melaksanakan kegiatannya pastilah tidak dapat dipisahkan dari manajemennya dalam mengelola sumber dayanya, baik itu manusia. Namun dengan terus bertambahnya tekanan untuk selalu memenangkan kompetisi dan menjadi pemenang dalam bidang kerjanya, hasil kerja pegawai diharapkan untuk dapat berkembang dari masa ke masa. Pada satu perusahaan atau Instansi pemerintahan, pegawai menjadi penentu dan penggerak terciptanya kegiatan yang didasari dengan keterampilan yang dimiliki karyawan. Pegawai adalah aset berharga bagi perusahaan sebab mempunyai peranan yang penting pada suatu perusahaan dengan peran antara lain menjadi perencana, pemikir serta pemegang kendali setiap aktivitas di perusahaan. Pada prosesnya, suatu perusahaan pastilah mengalami rintangan dan hambatan yang yang muncul bisa dari sisi dalam perusahaan ataupun dari luar perusahaan (Utari, et al., 2021). Dinas Pendidikan Kebudayaan Kab. Kepulauan Meranti adalah satu dari sekian organisasi pemerintah yang bergerak di bidang pendidikan. Agar mampu menyediakan layanan yang optimal bagi warga yang berkepentingan, dilaksanakan beragam terobosan yang mampu menciptakan masyarakat lebih percaya pada kinerja Dinas 
Pendidikan Kebudayaan Kab.

Kepulauan Meranti sehingga tujuan organisasi dapat tercapai.

$$
\text { Peranan sumber daya }
$$

khususnya yang berbau manusiawi penting sangat penting demi terciptanya kelangsungan kinerja organisasi itu sendiri. Selaras dengan riset yang dilaksanakan oleh Nasution (2020) menunjukkan jika Semangat bekerja berdampak positif serta signifikan pada hasil kerja pegawai. Pratama serta Wardani (2017) juga menunjukkan jika semangat bekerja secara parsial berdampak signifikan pada hasil kerja pegawai. Deswita, dkk. (2018) dalam penelitiannya juga menunjukkan semangat kerja secara parsial berdampak signifikan pada hasil kerja karyawan Dinas Pendidikan Kebudayaan Kabupaten Indragiri Hulu.

Sesuai dengan riset yang dilakukan oleh Sugara, dkk. (2020) juga menunjukkan jika secara parsial variabel independen motivasi berdampak signifikan pada variabel dependen semangat bekerja. Kahpi, dkk. (2018) pada risetnya juga menunjukkan motivasi bekerja memiliki pengaruh positif serta signifikan pada semangat kerja pegawai. Nasution (2020) juga menjelaskan jika secara sendirisendiri, motivasi berdampak positif serta signifikan pada hasil kerja karyawan. Kemudian Budiman, dkk. (2015) dalam peneitiannya menjelaskan bahwa variabel motivasi berdampak signifikan pada semangat bekerja pegawai non manajerial bagian produksi. Sedangkan riset yang dilaksanakan oleh Feri, dkk. (2020) menyebutkan jika Motivasi berdampak negatif serta signifikan pada hasil kerja pegawai. Dari hasil

penelitian terdahulu $r$ tersebut,
mayoritas mengatakan motivasi
memiliki dampak yang signifikan
pada semangat kerja dan kinerja
karyawan meskipun ada yang
menyatakan motivasi tak memiliki
dampak yang signifikan pada
semangat kerja dan hasil kerja
karyawan, hal ini menjadi
memunculkan research gap pada
penelitian terdahulu.

Penelitian ini bertujuan untuk mendetesiskan kondisi motivasi kerja, semangat kerja dan kinerja pegawai di Dinas Pendidikan dan Kebudayaan Kabupaten Kepulauan Meranti. Untuk menguji dan menganalisis pengaruh motivasi kerja terhadap semangat kerja pegawai di Dinas Pendidikan dan Kebudayaan Kabupaten Kepulauan Meranti. Untuk menguji dan menganalisis pengaruh semangat kerja pegawai terhadap kinerja pegawai di Dinas Pendidikan dan Kebudayaan Kabupaten Kepulauan Meranti. Untuk menguji dan menganalisis pengaruh motivasi kerja terhadap kinerja pegawai di Dinas Pendidikan dan Kebudayaan Kabupaten Kepulauan Meranti. Untuk menguji dan menganalisis pengaruh motivasi kerja terhadap kinerja pegawai Dinas Pendidikan dan Kebudayaan Kabupaten Kepulauan Meranti melalui semangat kerja pegawai.

\section{TINJAUAN PUSTAKA}

Manajemen Sumber Daya Manusia

Manajemen sumberdaya khususnya di bidang daya manusia merupakan satu pendayagunaan dan penelolaan yang berfokus pada personal pegawai. Dayaguna dan kelola yang ada akan berkembang secara optimal pada lingkungan 
bekerja dengan tujuan mewujudkan target perusahaan serta mengembangkan personal karyawan (Mangkunegara, 2017:2). Pendapat Schuler, et al. yang dialih bahasakan Sutrisno (2017:6) manajemen sumber daya pada bidang manusia adalah pengungkapan mengenai betapa berharganya karyawan bagi perusahaan sebagai sumber daya yang utama dalam memberikan sumbangsih bagi target-target perusahaan, serta menjalankan fungsi yang ada serta produksi yang akan memastikan jika sumber daya yang tersedia mampu dimanfaatkan dengan maksimal dan memiliki rasa keadilan bagi tujuan personal, perusahaan serta lingkungan sekitarnya (Prasetyo, et al., 2021).

\section{Kinerja Pegawai}

Disiplin diungkapkan Fahmi (2016) kinerja merupakan keluaran yang didapati oleh satu bagian karyawan perusahaan yang memiliki sifat beroirientasi pada keuntungan yang didapatkan pada masa karyawan bekerja. Wibowo (2017) kinerja adalah keluaran bekerja yang memiliki relasi erat dengan target perusahaan, memberikan sumbangsih di sektor ekonomi. Bastian dalam Fahmi (2016) kinerja merupakan interpretasi tentang tahapan capaian penjalanan satu program/kegiatan/kebijakan tentang menggapai ratget yang telah ditentukan, visi serta misi perusahaan yang tertulis pada perencanaan strategis di perusahaan.

\section{Semangat Kerja}

Menurut Abdulhak dan Darmawan (2015:77) semangat dalam bekerja bisa dimaknai sebagai satu suasana ataupun iklim bekerja yang ada pada satu perusahaan yang menggambarkan rasa ingin saat menjalankan kerjanya serta memberikan dorongan pada karyawan untuk melakukan pekerjaan dengan produktif serta optimal. Soedarso (2015:104) menjabarkan jika semangat bekerja merupakan gambaran keadaan pegawai pada lingkungannya bekerja, jika memiliki semangat bekerja yang baik maka perusahaan mendapatkan nilai lebih seperti absensi yang rendah, rendahnya angka karyawan yang keluar masuk, serta produktivitas karyawan akan meningkat.

\section{Motivasi Kerja}

Individu menjalankan suatu upaya secara umum memiliki satu motif. Individu menjalankan satu hal secara disengaja pasti memiliki maksud dan tujuan yang dapat memberikan dorongan menjalankan satu upaya. Motif dasar pada individu yang dimaksud merupakan terdapatnya kebutuhan individu yang bersangkutan akan rasa bangga serta hormat dan finansial yang mumpuni (Donni dan Suwatno, 2013:171). Sama halnya dengan Hasibuan, (2016:92) yang menjelaskan motivasi bersumber dari kosa kata latin yakni (movere) bermakna mendorong. Motivasi adalah keadaan ataupun tenaga yang mampu memberikan dorongan individu pegawai secara 
terarah ataupun dengan tujuan yang pasti guna menggapai targer perusahaan ataupun organisasi.

\section{Hubungan Variabel Penelitian}

Kedisiplinan semangat bekerja yang dimiliki pegawai dapat memacu utnuk menggapai taraf prpduksi yang optimal, hingga akhirnya mampu mewujudkan target dari organisasi. Motivasi secara tepat sasaran yang dimasukan dalam pola pikir pegawai agar mereka berusaha dengan optimal pada saat menjalankan kerjanya, sebab jika perusahaan dapat mencapai targetnya serta berbagai capaian lainnya, maka kesejahteraan dari pegawau yang bekerja juga kan lebih terjamin (Syakur, et al., 2021).

Terdapatnya semangat bekerja yang ada, menjadikan berkerja semakin cepat diselesaikan dari biasanya, ketidak hadiran bisa diminimalkan serta peluang kepindahan pegawai dapat diminimalisir sehingga kerugian dari sisi SDM dapai dihindari. Sebab hal tersebut maka kemudian jika pada tiap perusahaan terus memperjuangkan supaya pagawai yang ada memiliki kesadaran yang baik akan perusahaan tempatnya bekerja, kemudian pegawai yang dimaksud menjadi sangat mengharapkan mempunyai kesadaran bekerja yang baik dikarenakan dengan kesadaran kerja yang baik diprediksikan semangat dalam bekerja juga dapat bertambah disebabkan semangat dalam bekerja sebagai dasarnya merupakan wujud dari moral dalam bekerja dengan kategori tinggi.

Menurut Stoner pada Notoatmodjo (2015:125) kinerja/hasil kerja pada individu pegawai ataupun pekerja dapat diberikan pengaruh oleh kemampuan, persepsi dan motivasi. Ketika karyawan mempunyai dorongan untuk berprestasi dia akan berusaha menggapainya karena ketika karyawan sudah mendapatkan restasi maka karyawan tersebut akan mendapatkan pengakuan dari orang lain terhadap dirinya, maka dari itu karyawan akan selalu berusaha untuk memperbaiki dan meningkatkan kinerjanya (Utari, et al., 2020).

\section{Hipotesis}

Berdasarkan pada tinjauan pustaka dan hubungan variabel penelitian, maka hipotesis yang terbentuk pada riset ini yakni :

1. Motivasi kerja berpengaruh signifikan terhadap semangat kerja pegawai Dinas Pendidikan dan Kebudayaan Kabupaten Kepulauan Meranti.

2. Semangat kerja pegawai berpengaruh signifikan terhadap kinerja pegawai Dinas Pendidikan dan Kebudayaan Kabupaten Kepulauan Meranti.

3. Motivasi kerja berpengaruh signifikan terhadap kinerja pegawai Dinas Pendidikan dan Kebudayaan Kabupaten Kepulauan Meranti.

4. Motivasi kerja berpengaruh signifikan terhadap kinerja pegawai Dinas Pendidikan dan Kebudayaan Kabupaten Kepulauan 
Meranti melalui semangat kerja pegawai.

Berdasar pada landasan teori serta penelitian yang telah dilakukan sebelumnya, dapat digambarkan kerangka konsep penelitian yang terbentuk yakni.

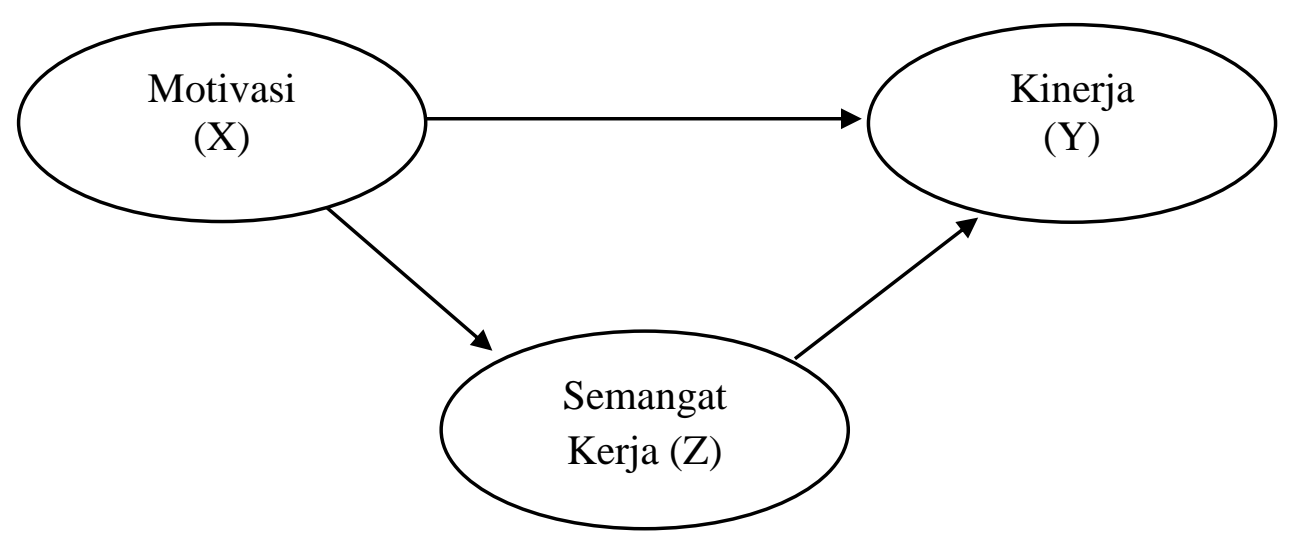

Gambar 1.

Kerangka Konseptual

\section{METODE PENELITIAN}

Riset yang dilakukan memiliki tujuan untuk menggambarkan relasi antar variabel bebas terhadap variabel terikat, sehingga macam riset yang diaplikasikan pada riset ini merupakan explanatory research. Riset menggunakan pendekatan kuantitatif. Data pada riset ini bersumer serta dilaksanakan di Dinas Pendidikan Kebudayaan Kabupaten Kepulauan Meranti Kab. Kepulauan Meranti, Riau.

Populasi pada riset ini yakni semua karyawan di Dinas Pendidikan Kebudayaan Kab. Kepulauan Meranti yang berjumlah 77 responden dengan rincian 32 pegawai PNS dan 45 pegawai non PNS. Karena dalam pelaksanaan penelitian peneliti tidak bisa ikut dalam sampel penelitian maka pada riset ini sampel ditetapkan sebesar 76 responden.
Data yang didapatkan kemudian dianalisa dengan model kuantitatif yang memakai metode path analysis. Path analysis dipergunakan guna menentukan besaran dampak variabel independen motivasi (X) pada variabel dependent kinerja pegawai (Y) melalui semangat kerja (Z). Selaras pada kerangka berpikir sehingga tercipta persamaan/ rumusan struktural yang berjumlah dua yakni persamaan/rumusan regresi yang menggambarkan relasi yang kemudian membentuk hipotesis. Dua persamaan yang tercipta yakni:

$$
\begin{aligned}
& Z=\rho z x X+\rho z \varepsilon 1 \\
& Y=\rho Y x X+\rho y z Z+\rho y \varepsilon 2
\end{aligned}
$$

Dimana:

$\mathrm{X}=$ Motivasi

$\mathrm{Z}=$ Semangat kerja

$\mathrm{Y}=$ Kinerja pegawai

$\rho=$ Koefisien korelasi

Terlihat dari kedua persamaan yang ada terselip unexplained 
variance yang diwakili $\varepsilon 1$ dan $\varepsilon 2$. Simbol $\varepsilon 1$ dan $\varepsilon 2$ dipergunakan sebagai wakil variabel lainnya yang berdampak pada $\mathrm{Z}$ serta $\mathrm{Y}$ namun variabel yang dimaksud tidak terliat pada model yang ada dalam riset. Proses identifikasi besaran nilai $\varepsilon$ diperoleh dari (1-adjusted $\mathrm{R}^{2}$ ).

\section{HASIL DAN PEMBAHASAN \\ Analisis Jalur Regresi Model I}

Analisa jalur regresi model I agar diketahui dampak motivasi pada semangat bekerja tertuang pada jalur pertama. Agar diketahui besarnya dampak variabel motivasi bekerja pada variabel semangat bekerja karyawan di Dinas Pendidikan Kebudayaan Kab. Kepulauan Meranti digunakan koefisiensi determinan (adjusted R square). Keluaran dari data yang diolah sehingga didapati hasil tabel dibawah.

Tabel 1

Hasil Uji Koefisien Determinasi $\left(\mathbf{R}^{2}\right)$

\begin{tabular}{llrrr}
\hline Model & R & R Square & $\begin{array}{c}\text { Adjusted R } \\
\text { Square }\end{array}$ & $\begin{array}{r}\text { Std. Error of } \\
\text { the Estimate }\end{array}$ \\
\hline 1 & $.326^{\mathrm{a}}$ & .106 & .094 & .38022 \\
\hline
\end{tabular}

Sumber:Data primer diolah, 2021.

Berdasar pada tabel 1 mampu terliat besaram koefisien determinasi $\left(\mathrm{R}^{2}\right) \quad$ bernilai 0,106. Temuan tersebut dapat dimaknai jika $10,6 \%$ besarnya semangat kerja karyawan di Dinas Pendidikan Kebudayaan Kabupaten Kepulauan Meranti terpengaruh oleh variabel bebas motivasi. Sementara lainnya bernilai 0,894 atau $89.4 \%$ terpengaruh oleh variabel lainnya yang berada diluar dari riset ini.

Hasil uji Coefficients berdasarkan perhitungan yang dijalankan dengan bantuan SPSS ditampilkan pada Tabel 2.

Tabel 2

Coefficients Pengaruh Motivasi Terhadap Semangat Kerja

\begin{tabular}{|c|c|c|c|c|c|}
\hline \multirow[b]{2}{*}{ Model } & \multicolumn{2}{|c|}{$\begin{array}{c}\text { Unstandardized } \\
\text { Coefficients }\end{array}$} & $\begin{array}{c}\text { Standardized } \\
\text { Coefficients }\end{array}$ & \multirow[b]{2}{*}{$\mathrm{t}$} & \multirow[b]{2}{*}{ Sig. } \\
\hline & B & $\begin{array}{l}\text { Std. } \\
\text { Error }\end{array}$ & Beta & & \\
\hline 1 (Constant) & 2.268 & .439 & & 5.171 & .000 \\
\hline Motivasi & .341 & .115 & .326 & 2.965 & .004 \\
\hline
\end{tabular}

Sumber: Data primer, diolah, 2021.

Terlihat dari tabel 2 model regresi pada semangat kerja pada halhal yang mempengaruhinya yakni motivasi yang kemudian dirumuskan : $Z=0,326 X+0,894$
Terlihat persamaan regresi, menggambarkan jika variabel motivasi memiliki arah/sifat koefisiensi regresial yang positif serta sebanding lurus pada semangat 
bekerja pegawai, hal ini 0.05). temuan yang ada menunjukan menggambarkan jika variabel jika motivasi memiliki dampak motivasi dapat menghasilkan dampak yang signifikan pada semangat kerja. positif pada semangat bekerja Analisis Jalur Regresi Model II pegawai. Temuan dari pengujian dampak motivasi pada semangat bekerja yang terbentuk adalah :

Ho: Tidak ada pengaruh motivasi terhadap semangat kerja

H1 : Motivasi mempunyai pengaruh dan signifikan terhadap semangat kerja Berpedoman pada nilai thitung sebesar 2,965 dengan signifikansi bernilai 0,004, disebabkan nilai pvalue bernilai kecil dari taraf signifikasi $\alpha=5 \%$ atau $(0,004<$

Analisis jalur regresi model I supaya diketahui dampak motivasi pada semangat bekerja melalui jalur pertama. Agar diketahui besarnya dampak variabel motivasi bekerja pada variabel semangat bekerja pegawai di Dinas Pendidikan Kebudayaan Kab. Kepulauan Meranti digunakan koefisiensi determinan (adjusted R square). Keluaran pada data yang diolah sehingga didapati hasil tabel dibawah.

Tabel 3

Hasil Uji Koefisien Determinasi $\left(\mathbf{R}^{\mathbf{2}}\right)$

\begin{tabular}{llrrr}
\hline Model & $\mathrm{R}$ & $\mathrm{R}$ Square & $\begin{array}{c}\text { Adjusted R } \\
\text { Square }\end{array}$ & $\begin{array}{r}\text { Std. Error of } \\
\text { the Estimate }\end{array}$ \\
\hline 1 & $.347^{\mathrm{a}}$ & .120 & .096 & .23494 \\
\hline
\end{tabular}

Sumber: Data primer, diolah, 2021.

Berdasarkan tabel 3 kemudian terlihat besaran koefisien determinasi $\left(\mathrm{R}^{2}\right)$ bernilai 0,120 . Temuan tersebut dapat dimaknai jika $12 \%$ besarnya semangat kerja karyawan di Dinas Pendidikan Kebudayaan Kab. Kepulauan Meranti terpengaruh oleh variabel bebas motivasi. Kemudian lainnya bernilai 0,88 atau $88 \%$ terpengaruh oleh variabel lainnya yang tidak terdapat pada riset yang dijalankan.

Keluaran olah data pada Coefficients berdasarkan perhitungan memakai bantuan SPSS ditampilkan dibawah.

Tabel 4

Coefficients Pengaruh Motivasi Terhadap Semangat Kerja

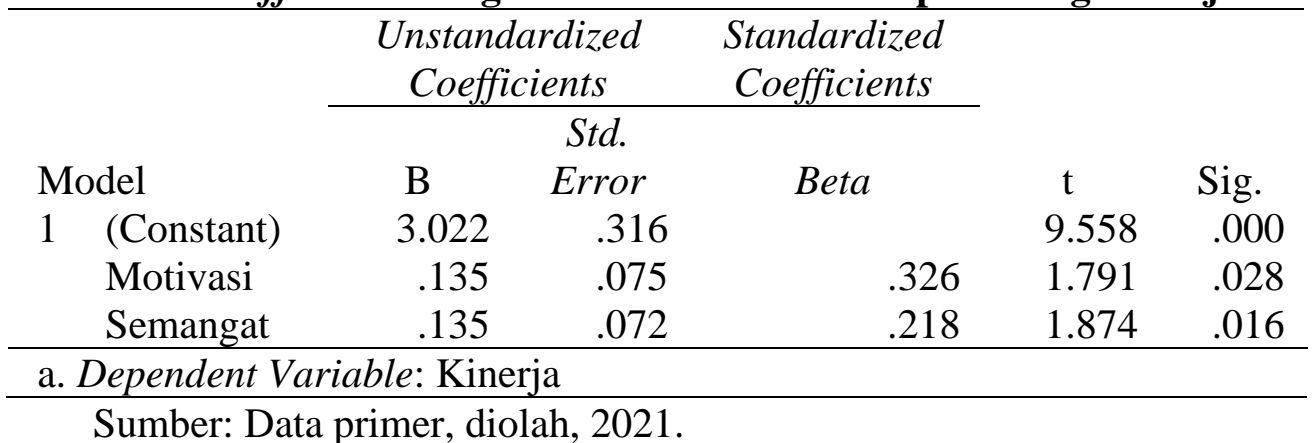


Berdasar tabel 4 model regresi pada semangat kerja untuk ha-hal yang mempengaruhinya yaitu motivasi antara lain:

$\mathrm{Y}=0,208 \mathrm{X}+0,218 \mathrm{Z}+0,880$

Berdasark persamaan regresi, terlihat jika variabel motivasi memiliki arahan koefisiensi regresi bernilai positif atau berbentuk lurus/straight pada hasil kinerja pegawai, temuan ini menggambarkan jika variabel motivasi dapat menghasilkan dampak positif pada kinerja/hasil kerja pegawai. Begitu juga variabel semangat bekerja memiliki arah/sifat koefisiensi regresi yang positif serta sebanding lurus/straight pada kinerja pegawai, temuan ini menggambarkan jika variabel semangat bekerja dapat menghasilkan dampak positif pada kinerja pegawai. Temuan uji dampak motivasi pada kinerja pegawai yang kemudian terbentuk :

Ho: Tidak ada pengaruh motivasi terhadap kinerja pegawai

H1 : $\begin{aligned} & \text { Motivasi mempunyai } \\ & \text { pengaruh dan signifikan }\end{aligned}$
terhadap kinerja pegawai
Berpedoman pada angka
thitung bernilai 1,791 pada taraf signifikan bernilai 0,028 , disebabkan nilai $p$-value lebih sedikit daripada nilai signifikasi $\alpha=5 \%$ atau $(0,028$ $<$ 0,05). Hal ini menunjukkan jika motivasi memiliki dampak yang signifikan pada kinerja pegawai.

Temuan uji atas dampak semangat bekerja pada kinerja karyawan adalah sebagai berikut:

Ho: Tidak ada pengaruh semangat kerja terhadap kinerja pegawai

H1 : Semangat kerja mempunyai pengaruh dan signifikan terhadap kinerja pegawai

Berpedoman pada nilai thitung sebesar 1,874 dengan signifikansi bernilai 0,016 , disebabkan nilai pvalue lebih kecil dari taraf signifikasi $\alpha=5 \%$ atau $(0,016<0,05)$. Hal ini menunjukkan bahwa semangat bekerja memiliki dampak yang signifikan pada kinerja/hasil kerja karyawan.

Analisis Pengaruh Total Motivasi
dan Semangat Kerja terhadap
Kinerja
Berdasar persamaan atas berpengaruh yang dijabarkan sebelumnya, bahwa dengan utuh kemudian tercipta alur pengaruh yang berbentuk berikut ini:

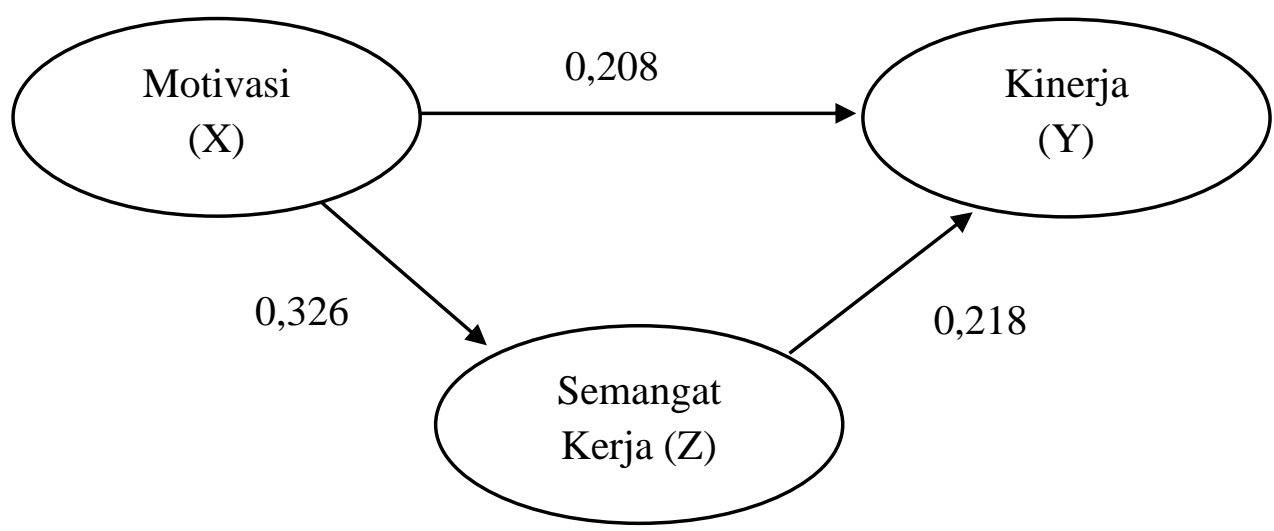

Gambar 2.

Hasil Analisis Jalur antara X, Z dan Y 
Berdasar gambar 2. hingga bisa dijabarkan dampak langsung serta tak langsung dari variabel motivasi (X), pada kinerja (Y) melalui semangat kerja (Z).

1. Dampak langsung motivasi (X) pada kinerja (Y) adalah bernilai 0,208 atau bernilai 20,8 persen.

2. Dampak tak langsung motivasi (X) pada kinerja (Y) melalui motivasi $(\mathrm{Z})$ adalah sebesar 0,326 $\mathrm{X} 0,218=0,071$ atau sebesar 7,1 persen.

3. Dampak total kompensasi (X) pada kinerja (Y) melalui motivasi 0,326 $+0,071=0,397$ atau sebesar 39,7 persen.

Berdasar pengujian analisa jalur, temuan dampak langsung serta tak langsung dari motivasi (X) pada kinerja (Y) melalui semangat kerja (Z) didapati temuan jika dampak langsung lebih kecil dibanding dampak tak langsung. Hipotesis yang menyatakan " Motivasi bekerja berdampak signifikan pada kinerja/hasil kerja karyawan Dinas Pendidikan Kebudayaan Kab. Kepulauan Meranti melalui semangat kerja pegawai" diterima atau terbukti.

\section{Pembahasan}

Motivasi Kerja berada pada indikasi bagus. Temuan yang ada menggambarkan jika Motivasi Kerja yang berindikator Target kerja, Kualitas kerja, Komunikasi, Persahabatan, Pemimpin, Keteladanan di Dinas Pendidikan dan Kebudayaan Kabupaten Kepulauan Meranti sudah bagus. Dinilai dari seluruh responden memberikan penilaian bagus terhadap faktor motivasi kerja, namun dari keseluruhan pernyataan yang ada terdapat faktor yang memiliki skor rerata tinggi yakni pegawai dapat bekerja dengan baik agar dapat menjadi teladan bagi pegawai lainnya, sedangkan skor rata-rata terendah adalah pegawai memiliki keinginan untuk menjadi pimpinan di tempat kerja.

Semangat Kerja berada pada indikasi bagus. Temuan yang ada menggambarkan jika Semangat Kerja yang berindikator perhatian pada kebutuhan rohani, gaji yang cukup, penempatan pegawai pada posisi yang sesuai, tercipta rasa santai, merasa masa depan yang aman, dan fasilitas bekerja yang menunjang di Dinas Pendidikan Kebudayaan Kabupaten Kepulauan Meranti sudah bagus. Meskipun demikian perlu adanya penyesuaian pada pemberian gaji dengan pemberian tunjangan lainnya kepada pegawai yang memiliki semangat kerja yang tinggi.

Kinerja pegawai berada pada indikasi bagus. Temuan yang ada menggambarkan jika kinerja pegawai yang berindikator kerjasama, kejujuran pegawai, pengetahuan pada pekerjaan, mutu pekerjaan, kehadiran, inisiatif, sikap, keandalan, tanggung jawab serta manajemen waktu kerja di Dinas Pendidikan Kebudayaan Kab. Kepulauan Meranti sudah bagus. Meskipun demikian pempinan perlu memberikan himbauan, bila perlu melakukan pendekatan secara personel kepada pegawai agar selalu melaksanakan dan melaporkan setiap pekerjaan yang menjadi tanggung jawabnya.

Berdasar analisa pada keluaran maupun hasil pada riset ini didapati jika motivasi mempunyai dampak signifikan pada semangat kerja karyawan Dinas Pendidikan dan Kebudayaan Kabupaten Kepulauan Meranti. Motivasi Kerja dalam riset ini terdiri dari Target kerja, Kualitas 
kerja, Komunikasi, Persahabatan, Pemimpin, Keteladanan di Dinas Pendidikan Kebudayaan Kab. Kepulauan Meranti secara keseluruhan responden menilai bagus, meskipun demikian apabila Dinas Pendidikan Kebudayaan Kabupaten Kepulauan Meranti ingin lebih meningkatkan motivasi kerja pegawainya perlu adanya pelatihan tentang kepemimpinan agar setiap pegawai dapat memiliki jiwa kepemimpinan dalam mendukung motivasi kerjanya.

Berdasar analisa pada keluaran maupun hasil pada riset ini didapati jika semangat kerja mempunyai dampak signifikan pada hasil kerja karyawan Dinas Pendidikan Kebudayaan Kab. Kepulauan Meranti. Semangat Kerja dalam riset yang dilakukan terdiri dari pendapatan yang memadai, perhatian kebutuhan rohani, tercipta rasa santai, penempatan pegawai di tempat yang sesuai, perasaan akan masa depan yang aman, serta fasilitas bekerja yang menunjang di Dinas Pendidikan Kebudayaan Kab. Kepulauan Meranti sudah bagus.

Berdasar analisa pada keluaran maupun hasil pada riset ini didapati jika motivasi mempunyai dampak signifikan pada kinerja/hasil kerja karyawan Dinas Pendidikan Kebudayaan Kab. Kepulauan Meranti. Disamping itu motivasi juga mempunyai dampak signifikan pada kinerja/hasil kerja karyawan Dinas Pendidikan Kebudayaan Kab. Kepulauan Meranti melalui semangat kerja. Motivasi berdampak signifikan pada kinerja/hasil kerja pegawai. Semangat kerja berdampak signifikan pada kinerja/hasil kerja pegawai. Motivasi berdampak signifikan pada kinerja/hasil kerja melalui semangat bekerja.

\section{SIMPULAN DAN SARAN Simpulan}

Berdasar analisis data yang dilaksanakan di bagian diatas, penulis memperoleh kesimpulan yang tersusun antara lain:

1. Motivasi kerja, semangat bekerja serta kinerja/hasil kerja karyawan di Dinas Pendidikan Kebudayaan Kab. Kepulauan Meranti semuanya memiliki kondisi yang bagus

2. Motivasi kerja memiliki dampak positif serta signifikan semangat bekerja karyawan di Dinas Pendidikan Kebudayaan Kab. Kepulauan Meranti dengan pengaruh bernilai 32,6 persen.

3. Semangat kerja pegawai berdampak positif serta signifikan pada kinerja/hasil kerja pegawai di Dinas Pendidikan Kebudayaan Kab. Kepulauan Meranti dengan pengaruh sebesar 21,8 persen.

4. Motivasi kerja mempunyai dampak positif serta signifikan hasil kinerja pegawai di Dinas Pendidikan Kebudayaan Kab. Kepulauan Meranti dengan pengaruh sebesar 20,8 persen.

5. Motivasi kerja mempunyai dampak positif serta signifikan pada hasil kinerja pegawai Dinas Pendidikan Kebudayaan Kab. Kepulauan Meranti melalui semangat kerja pegawai dengan pengaruh sebesar 39,7 persen.

\section{Saran}

Adapun saran yang dapat penulis berikan bagi kemajuan Dinas Pendidikan Kebudayaan Kab. Kepulauan Meranti pada hasil riset ini diantara sebagai berikut:

1. Pegawai perlu diberikan pelatihan tentang kepemimpinan agar setiap 
pegawai dapat memiliki jiwa kepemimpinan dalam mendukung motivasi kerjanya sehingga pegawai dapat lebih bersemangat lagi dan pada akhirnya dapat meningkatkan kinerja pegawai.

2. Pemberian gaji dapat disesuaikan dengan pemberian tunjangan lainnya kepada gaji yang mempunyai semangat bekerja tinggi sehingga kinerja pegawai mampu meningkat.

3. Pimpinan perlu memberikan himbauan, bila perlu melakukan pendekatan secara personel kepada pegawai agar selalu melaksanakan dan melaporkan setiap pekerjaan yang menjadi tanggung jawabnya.

4. Untuk penelitian selanjutnya yang membahas mengenai kinerja/hasil kerja pegawai di Dinas Pendidikan Kebudayaan Kab. Kepulauan Meranti perlu mencari variabel lainnya yang tidak terdapat pada riset ini karena dalam riset ini variabel yang digunakan pengaruhnya masih di bawah $50 \%$ terhadap kinerja pegawai.

\section{DAFTAR PUSTAKA}

Abdulhak, I. dan Darmawan, D., 2015, Teknologi Pendidikan, Bandung : PT. Remaja Rosdakarya

Deswita Pamelia, Indrawati Mei dan Utari Woro, 2018, Pengaruh Kompensasi, Semangat Kerja Dan Lingkungan Kerja Terhadap Kinerja Pegawai Dinas Pendidikan Dan Kebudayan Kabupaten Indragiri Hulu, MAP (Jurnal Manajemen dan Administrasi Publik)Volume 1,Nomor 1,JanuariMaret 2018:101-109
Fahmi, Irham, 2016, Manajemen Sumber Daya Manusia Teori dan Aplikasi, Bandung: Alfabeta.

Feri Setria, Adi Rahmat, Bambang Supeno, 2020, Pengaruh Motivasi, Gaya Kepemimpinan Transformasional dan Budaya Organisasi Terhadap Kinerja Karyawan Melalui Kepuasan Kerja Sebagai Variabel Intervening Studi Pada PT. Champion Kurnia Djaja Technologies, INOBIS: Jurnal Inovasi Bisnis dan Manajemen Indonesia, Volume 4, Nomor 1, Desember 2020

Hasibuan, Malayu S.P., 2016, Manajemen Sumber Daya Manusia, Edisi. Revisi, Jakarta: Penerbit PT Bumi Aksara

Kahpi Heri Sapari, Zaenal Abidin, Raga Aqino dan Guli, 2020, Pengaruh Lingkungan Kerja Dan Motivasi Kerja Terhadap Semangat Kerja Di PT. Indah Kiat Pulp And Paper Tbk, Jurnal Ekonomi dan Publik, Vol. 16 No. 2 Agustus 2020

Mangkunegara, A.A. Anwar Prabu, 2017, Manajemen Sumber Daya Manusia. Perusahaan, Bandung : Remaja Rosdakarya.

Nasution Indra Bakti, 2020, Pengaruh Motivasi, Kesejahteraan Dan Semangat Kerja Terhadap Kinerja Pegawai PT. Agrotech Pesticide Industry Medan, Jurnal Riset Manajemen \& Bisnis (JRMB), Vol.5 No.1 Juni 2020 
Notoatmodjo, Soekidjo, 2015, Pengembangan Sumber Daya. Manusia, Jakarta: Rineka Cipta

Prasetyo, Indra; Aliyyah, Nabilah; Rusdiyanto; Utari, Woro; Suprapti, Sri; Kartika, Chandra; Winarko, Ruddy; Chamariyah; Panglipursari, Dwi Lesno; Muninghar, Halimah, Nur; Aminatuzzuhro; Indrawati, Mei; Junus, Onong: Herli, Mohammad; Hafidhah; Kustiningsih, Nanik; Gazali; Kusuma, Adriani; Aina, Muslimatul; Bustaram, Isnain; Risal, Zef; Zainurrafiqi; Amar, Siti Salama; Umah, Khoiroh; Khadijah, Susan Novitasari; Gustomi, Mono Pratiko; Irawan, Hendra; Rochman, Arif Syafi'ur; Pramitasari, Dini Ayu; Farid, Muhammad Miftah; Kalbuana, Nawang. 2021. Effects of Organizational Communication Climate and Employee Retention Toward Employee Performance. Journal of Legal, Ethical and Regulatory. Vol: 24 Issue: $1 \mathrm{~S}$ (2021)

Pratama Abdul Aziz Nugraha dan Wardani Aprina, 2017, Pengaruh Kemampuan Kerja dan Semangat Kerja Terhadap Kinerja Karyawan Melalui Kepuasan Kerja (Studi Kasus Bank Syariah Mandiri Kantor Cabang Kendal), Jurnal Muqtasid, 8(2) 2017: 119-129

Soedarso, Sri Widodo. 2015. Sistem Informasi Manajemen. Bandung: Manggu Media.
Sugara Franky, Adji Setyo dan Chamidah Siti, 2020, Pengaruh Komunikasi, Motivasi, dan Lingkungan Kerja Fisik terhadap Semangat Kerja Karyawan Ud. Sukri Dana Abadi Ponorogo. Jurnal Ekonomi, Manajemen dan Akuntansi, Vol. 4 No. 12020. Hal: 46-57

Sutrisno, E., 2017, Manajemen Sumber Daya Manusia, Jakarta: Kencana

Syakur, Abd.; Utari, Woro; Chamariyah. Correlation between Organizational Roles, OBC, and Organizational Commitment toward Employees of the Limited Liability Company of State Electricity Company of APJ Jember. 2021. Budapest International Research and Critics Institute (BIRCIJournal) : Humanities. Vol 4, No 2 (2021)

Utari, Woro; Iswoyo, Andi; Chamariyah; Mardiana, Fitra; Hidayat, Widi; Waras; Rusdiyanto. 2021. Effect Of Work Training, Competency and Job Satisfaction on Employee Productivity: A Case Study Indonesia. Review Of International Geographical Education. 11(4), Winter, (2021)

Utari, Woro; Setiawati, Ratna; and Fauzia, Nur. 2020. The Effect of Work Discipline on the Performance of Employees in Compensation Mediation: A Case Study Indonesia. 
Journal of Applied Management and Accounting Science. (JAMAS)

(Syaifuddin, Indra Prasetyo, Mei Indrawati 59 - 71)

Vol 3, No 1, Desember 2021

PalArch's Journal of

Archaeology of

Egypt/Egyptology 17 (9) (2020)

Wibowo, 2017, Manajemen Kinerja.

Edisi Ke-5, Jakarta: Rajawali

Press. 